\title{
Characterization of biochar of pine pellet
}

\author{
Lidya B. Santos ${ }^{1} \cdot$ Maria V. Striebeck $^{2} \cdot$ Marisa S. Crespi ${ }^{3}$. \\ Clovis A. Ribeiro ${ }^{3} \cdot$ Marcelo De Julio $^{1}$
}

Received: 28 October 2014 / Accepted: 2 May 2015/Published online: 27 May 2015

(C) Akadémiai Kiadó, Budapest, Hungary 2015

\begin{abstract}
Recently, biochar was introduced as a bioadsorbent material to remove various contaminants in effluents, such as pigments, dyes, heavy metals, naphthalene, 1-naphthol, atrazine, phosphorus and some macro- and micronutrients. Therefore, biochar of biomass residue pellet obtained for slow pyrolysis was evaluated as an alternative process for the potential utilization as chemical contaminant remover with low cost. Thus, the main objective of this work was to produce biochar from pine residue pellet for subsequent use of the same as a potential adsorbent for effluent treatment. In order to perform the characterization, samples of biochar from pine pellet were produced using several heating rates $\left(5-30{ }^{\circ} \mathrm{C} \min ^{-1}\right)$, residence temperatures $\left(200,280\right.$ and $\left.570{ }^{\circ} \mathrm{C}\right)$ and residence times ( $1 \mathrm{~h}$ and half an hour). The process adopted led to a rapid degradation of the raw material (pine pellet) associated with an intense generation of volatile compounds, conditions that led to a reduction in density and establishment of porous structure. Biochars had basic character $(\mathrm{pH}$ 8.47), predominance of aromatic structures, low moisture content (0.9-1.8\%), low ash content $(1.25-1.80 \%)$ and high thermal stability. Low humidity
\end{abstract}

Clovis A. Ribeiro

ribeiroc@iq.unesp.br

1 Building Engineering Department, Aeronautical Institute of Technology, Marechal Eduardo Gomes Square 50, Sao Jose dos Campos 12228-900, Brazil

2 Chemical Engineering Department, College Engineering, National University of Buenos Aires Province Center, del Valle Avenue 5737, B7400JWI Olavarria, Argentina

3 Analytical Chemistry Department, Chemistry Institute, São Paulo State University, Professor Francisco Degni Street 55, Araraquara 14800-060, Brazil favors the adsorption and an improvement in the conservation during transport and storage.

Keywords Biochar of biomass residues - Pyrolysis · Pine pellet . Thermal behavior

\section{Introduction}

Chemical contaminant removal in the environment has been a major technological challenge, because oftentimes, conventional treatment technologies are not able to do it efficiently. For this reason, the search for low-cost, effective technologies of contaminant removal has grown considerably.

Among the various types of wastewater treatment, the adsorptive separation process results in high geometric selectivity or form, as well as energy or electrostatic selectivity [1]. In this sense, biochar, a porous carbon adsorbent material with the potential to retain contaminants, plays a crucial role in risk management and disposal of pollutants [2-6].

In addition to having high carbon content, biochar has large surface area due to its porosity as a result of the burning process. Due to biochar not be a standard product, its chemical, physical and physicochemical characteristics depend on the firing process and its consequences (type pyrolysis temperature, retention time, addition of oxygen), besides the type and particle size of the biomass.

The firing conditions influence the degree of aromatic compounds and the adsorption characteristics of biochar. The higher the temperature, the retention time and the presence of air, the greater the level of aromatics in biochar [7].

Recently, biochar was introduced as a bioadsorbent material for removing several contaminants in effluents, such as pigments [8,9], dyes [10], heavy metals [11-16], 
naphthalene, 1-naphthol [5], atrazine [14], phosphorus [17] and some macro- and micronutrients.

Importantly, agroforestry waste resources are of low cost and available as a source of biomass energy and biochar precursor material. Thus, the main objective of this work was to produce biochar from pine pellet for subsequent use as a potential adsorbent for effluent treatment.

\section{Materials and methods}

The biomass used in the study constituted of residues from Araucaria angustifolia (pine pellets) and was obtained from the BrBiomassa Company, Maringa, Parana State, Brazil. The development process of biochars made in this work consisted of subjecting the sample to a slow pyrolysis (since it presents the highest yield in solids) in a muffle furnace under inert atmosphere and atmospheric pressure, following several temperature settings $\left(200,280\right.$ and $\left.570{ }^{\circ} \mathrm{C}\right)$ and residence times ( $1 \mathrm{~h}$ and a half an hour), in addition to varying the heating rate $\left(5-30{ }^{\circ} \mathrm{C} \min ^{-1}\right)$.

Nitrogen adsorption technique, the point zero of charge (PZC), infrared spectroscopy (FTIR), scanning electron microscopy (SEM, FEG), nuclear magnetic resonance (NMR), $\mathrm{X}$-ray spectroscopy, adsorbent density analysis and thermal analysis were used for physicochemical characterization.

\section{Thermal stability evaluation}

The thermal stability evaluation of the biochar and pellet samples was performed by thermal gravimetric analysis, in an apparatus SDT-2960 from TA Instruments. Samples around $35 \mathrm{mg}$ were disposed in alumina pan, under the atmosphere of nitrogen and air (gas flow of $50 \mathrm{~mL} \mathrm{~min}^{-1}$ ) at a heating rate of $10-30{ }^{\circ} \mathrm{C} \mathrm{min}^{-1}$, from ambient temperature $\left( \pm 25^{\circ} \mathrm{C}\right)$ to $850{ }^{\circ} \mathrm{C}$.

\section{Adsorption-desorption isotherm of nitrogen- determination of specific surface area}

Adsorption-desorption of nitrogen measures was performed using a Micromeritics equipment, model ASAP 2000, with the ASAP 2010 software, version 5.01, at liquid nitrogen temperature $(77 \mathrm{~K})$. The textural parameters were determined from the obtained isotherms.

From the nitrogen adsorption and isotherm of desorption curves, specific surface area (BET method) and the pore size distribution (BJH) were obtained, respectively [19].

\section{Determination of the point of zero charge (PZC)}

The point of zero charge (PZC) or isoelectric point is defined as the $\mathrm{pH}$ at which the surface of the adsorbent has a neutral charge. The methodology used to determine them is called "method of 11 points" [20, 21]. The procedure consists of making a mixture of $50 \mathrm{mg}$ of adsorbents in $50 \mathrm{~mL}$ of aqueous in 11 different conditions of initial $\mathrm{pH}$ $(2,3,4,5,6,7,8,9,10,11,12)$, adjusted with $\mathrm{NaOH}$ or $\mathrm{HCl}$ solutions of $0.1 \mathrm{~mol} \mathrm{~L}^{-1}$, and measuring the equilibrium $\mathrm{pH}$ after $24 \mathrm{~h}$. From the plot of final $\mathrm{pH}$ versus initial $\mathrm{pH}$, the $\mathrm{PCZ}$, which corresponds to the range in which the final $\mathrm{pH}$ remains constant irrespective of the initial $\mathrm{pH}$, can be obtained.

\section{Scanning electron microscopy (SEM)}

The morphology of biochars was evaluated by SEM, with micrographs generated by topographic contrast through an electron microscope (SEM, Topcon, Model SM300). Only for pellets, coating with a thin layer of gold, conductive material, was necessary to generate the images.

EDS analyses were performed on a FEG SEM equipment (JEOL, model 7500F) coupled with EDS (energy analyzer of X-rays scattered).

\section{Particle density}

The bulk density is the mass of sample per volume occupied by the particle (solid and internal pore volume). The particle density of the biochar was determined by determining the mass of the sample in a calculated volume using a caliper (ASTM D 792) [22].

\section{Porosity}

The porosity of coal was obtained from the data of particle density and true density, by Eq. 1 [23]:

$P(\%)=100-(\mathrm{DA} \times 100) / \mathrm{DV}$

where $P(\%)$ is the porosity, DA is the particle density, and DV is the true density.

\section{X-ray diffraction patterns}

The mineralogical characterization of biochars was conducted by X-ray diffraction. Samples were performed in angle $2 \theta$ from 2 to $60^{\circ}$, with $\mathrm{CuK} \alpha$ radiation and graphite monochromator, at $35 \mathrm{kV}$ and $20 \mathrm{~mA}$, with diffraction apparatus X-ray SIEMENS D5000 model, DIFFRAC PLUS XRD Commander.

\section{Infrared spectroscopy-FTIR}

The absorption spectroscopy in the infrared region is made to determine the frequency of vibrations of the functional groups present in the coal. The samples of biochars were 
dried in an oven for a period of $12 \mathrm{~h}$ at $100{ }^{\circ} \mathrm{C}$. Subsequently, they were powdered and mixed with $\mathrm{KBr}$ at a ratio of $5 \%$ biochar. The spectrum of reading (Nicolet TermoScientific iS5 spectrophotometer) varied in the range of $4000-400 \mathrm{~cm}^{-1}$.

\section{Nuclear magnetic resonance (NMR)}

The effects of the temperature and residence time in the chemical structure of the biochar were observed by NMR ${ }^{13} \mathrm{C}$ VACP-MAS solid technique, using an Advance III $400 \mathrm{MHz}$ WB (Brüke) spectrometer.

\section{Moisture and ash}

Moisture and ash content were determined by gravimetric technique, according to ASTM D-3173, ASTM D-3174, ASTM D-1762 [24-26]. The samples were heated at $105{ }^{\circ} \mathrm{C}$ until constant mass. After that, the same sample was used for the determination of ash content, raising the temperature to $775^{\circ} \mathrm{C}$ maintaining for $1 \mathrm{~h}$.

\section{Results and discussion}

\section{Gravimetric yield of biochar}

The temperature is presented as the key process variable. Several experiments were performed in order to identify the influence of final pyrolysis temperature, for a given plant species on the yields of charcoal, liquid and gas. Data show that the behavior of the coal, when the pyrolysis temperature increases, is losing its volatile compound. Although the charcoal yield decreases with increasing temperature, there is a significant improvement in fixed carbon content, this indication of quality input [27].

Another notable impairment is observed when yields are compared in coal and liquids in different heating. Several studies show that it is possible to significantly increase the recovery of liquid products by increasing the heating rate [28-30]. To the low heating rate, the temperature reaches a particular value, where a higher rate of thermal decomposition of biomass components occurs, there is a reduced speed and output the newly formed components of the system. To remain in the system under high temperature, the newly formed components suffer further decomposition reactions (secondary reactions), mainly being converted into compounds of lower molecular mass (in most gases, such as $\mathrm{CO}_{2}$, $\mathrm{CO}$ and $\left.\mathrm{H}_{2} \mathrm{O}\right)$ and biochar $[31,32]$.

According to Tables 1 and 2, there was a lower yield of biochar in high temperatures of residence and high heating rates, corroborating the results found in the literature $[13,18]$. Thus, the reactions of secondary thermal
Table 1 Gravimetric yield of biochar as a function of heating rate for a pyrolysis temperature of $570{ }^{\circ} \mathrm{C}$

\begin{tabular}{ll}
\hline$\beta /{ }^{\circ} \mathrm{C} \min ^{-1}$ & Yield $/ \%$ \\
\hline 30 & 19.8 \\
25 & 20.0 \\
20 & 20.3 \\
15 & 21.1 \\
10 & 21.4 \\
5 & 22.4 \\
\hline
\end{tabular}

Table 2 Gravimetric yield of biochar as a function of temperature and residence time for a heating rate of $10{ }^{\circ} \mathrm{C} \mathrm{min}{ }^{-1}$

\begin{tabular}{lll}
\hline $\operatorname{tr} / \mathrm{min}$ & $T /{ }^{\circ} \mathrm{C}$ & Yield $/ \%$ \\
\hline 30 & 200 & 27.4 \\
60 & 200 & 26.2 \\
30 & 280 & 24.2 \\
60 & 280 & 23.9 \\
30 & 570 & 21.4 \\
60 & 570 & 21.4 \\
\hline
\end{tabular}

decomposition contribute to increase the yield of biochar with the decrease in heating rate (Table 1). However, in this work, it is not possible to observe an increase in yield with increasing residence time. This phenomenon can be explained by the fact that the system used in the pyrolysis is not closed, allowing the removal of volatile as they were being produced.

Cellulose, hemicellulose and lignin are major constituents of the biomass taken into account in the studies of pyrolysis as a means of biomass energy utilization. Despite the importance of this three components in the process, the difficulty of implementation and the inaccuracy of quantification methods, along with the complexities of thermal reaction, is not common the quantification of lignin, cellulose and hemicellulose in the evaluated biomass [31]. For this reason, in this study, the content of cellulose, hemicellulose and lignin was not quantified in the pellet used in the study of pine. The lack of this information does not result in major problems in interpreting the results since the thermal decomposition of these components tends to occur in characteristic temperatures, independent of biomass studied.

Hemicellulose is the least stable of the three components of the biomass, and its thermal decomposition takes place in the range of $150-350{ }^{\circ} \mathrm{C}$ and a maximum rate of about $270{ }^{\circ} \mathrm{C}$. Cellulose has a chemical composition similar to the hemicellulose, but due to its crystalline arrangement, it is more resistant to thermal decomposition, which occurs in the range of $275-400{ }^{\circ} \mathrm{C}$, with maximum around $350{ }^{\circ} \mathrm{C}$. 
The lignin thermal decomposition occurs at $250-500{ }^{\circ} \mathrm{C}$, but without any temperature range in which the decomposition rate is more intense [33].

With this information, it can be inferred that the income which occurred on heating at $280{ }^{\circ} \mathrm{C}$ (yield above $25 \%$ ) is close to the average lignin content $(25.18 \%)$ plus a bit of holocellulose $(72 \%)$ found in samples of Pinus oocarpa [35], while the yield of coal pyrolysis at $570{ }^{\circ} \mathrm{C}$ (yield below $25 \%$ ) is close to the same lignin content found by the author, but already in a reduced percentage. This comparison is consistent with the knowledge that the lignin component whose content is at best correlates with the biomass yield of biochar, while cellulose and hemicellulose are mainly responsible for the production of bio-oil and non-condensable gases [34].

\section{Thermal gravimetric analysis}

The thermal decomposition resistance of the samples was also tested, and all samples exhibited high thermal stability compared with the pellet in nature, especially biochars produced at $570{ }^{\circ} \mathrm{C}$ of temperature residence (Figs. 1 and 2) and low heating rate (Fig. 3).

In the initial stage of heating of the samples was noted an event, commonly associated with loss of water or volatiles present in the samples. Patterns of decomposition of biochars were not similar to the pellet. Because biochar had undergone a previous heat treatment thermal analysis, it has a lower mass loss in the first event of thermal decomposition (Figs. 1, 2), a characteristic of the hemicellulose decomposition. It was observed that, under nitrogen atmosphere, the biochars only had a small decomposition above temperatures which were produced.

The mass loss in the first event of decomposition, under an atmosphere of air, calculated on the mass of the sample without the moisture content, was $71 \%$ for the pellet. Although this value included the mass loss from the decomposition of other wood components, it is similar to the sum of hemicellulose and cellulose in pine [35]. For biochars, this mass loss varied from 35 to $44 \%$, suggesting that this reduction in mass loss is linked to the loss of hemicellulose from the preliminary heat treatment of biochar production.

The second thermal event appears at $470{ }^{\circ} \mathrm{C}$ in the pellet and at 475,580 and $630{ }^{\circ} \mathrm{C}$ in the biochar 200, 280 and $570{ }^{\circ} \mathrm{C}$, respectively, and resulted in reduction of 13,45 , 55 , and $41 \%$ of dry weight, respectively. The highest temperature to biochar is due to the partial transformation undergone by cellulose with thermal pretreatment, increasing its temperature resistance [36]. The highest mass loss of these biochars associated with this second event must have occurred because of its enrichment in cellulose, caused by the previous decomposition of hemicellulose.

The third event of mass loss reinforces this hypothesis, with identical pattern of thermal decomposition among biochars, which culminated in the loss of additional mass of 13,4 and $11 \%$ for biochar 200,280 and $570{ }^{\circ} \mathrm{C}$, respectively, with heating up to $850{ }^{\circ} \mathrm{C}$.

The thermogravimetric analysis shows that the decomposition mechanism of biochar could suggest the time of decompositions; furthermore, this analysis shows which atmosphere is more reactive and accelerates the decomposition process. It is important because the biochar will be submersed in effluent for long time when it is used as an adsorbent.

\section{Nitrogen adsorption-desorption isotherm}

The structural properties of the adsorbents are based on two important characteristics: pore size and surface area. A (a)

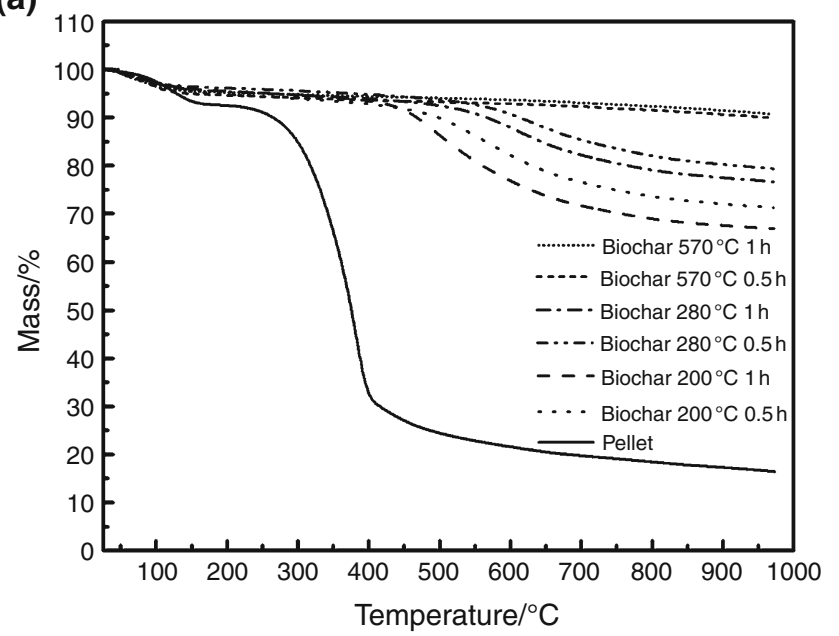

(b)

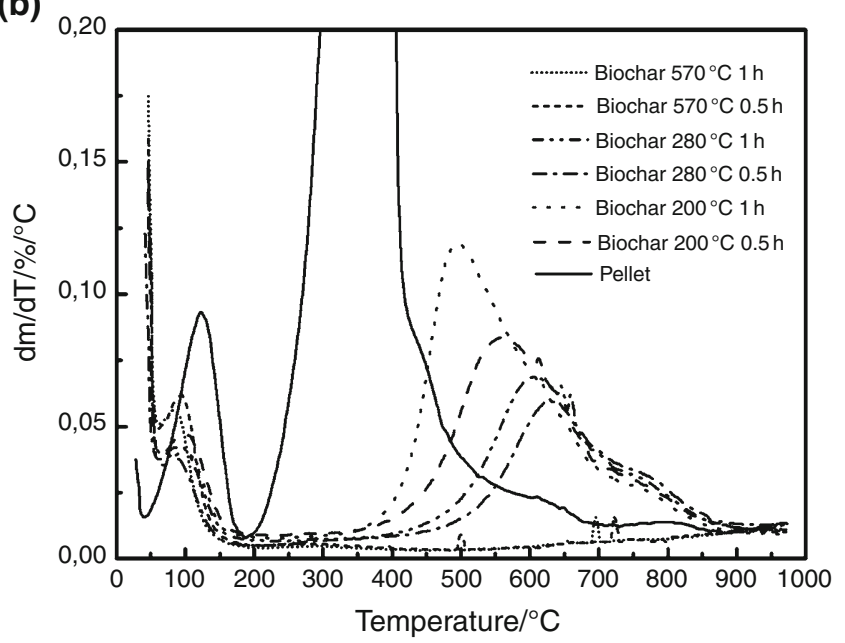

Fig. 1 TG (a) and DTG (b) curves (biochar and pine pellet) under nitrogen atmosphere and heating rate at $30{ }^{\circ} \mathrm{C} \min ^{-1}$ 
(a)

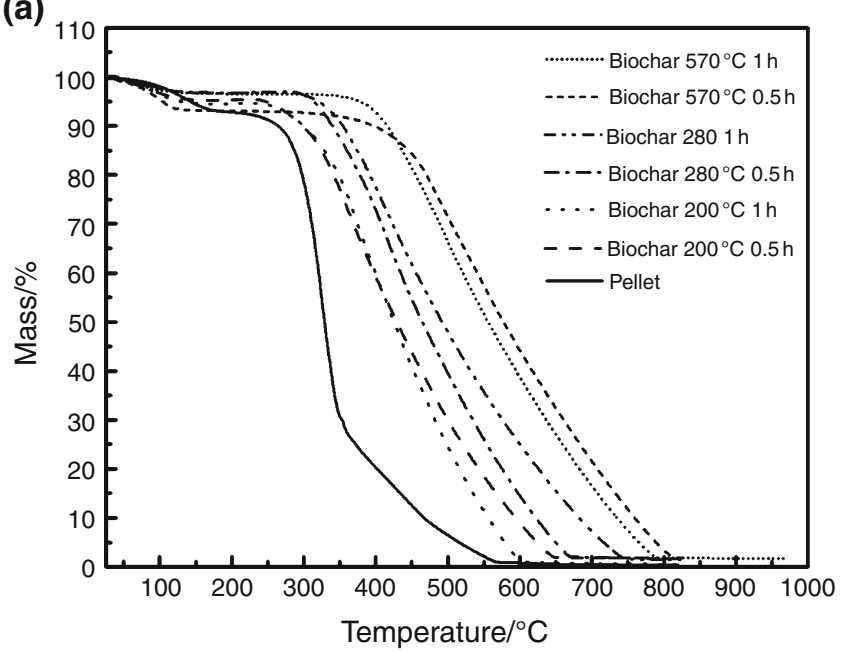

(b)

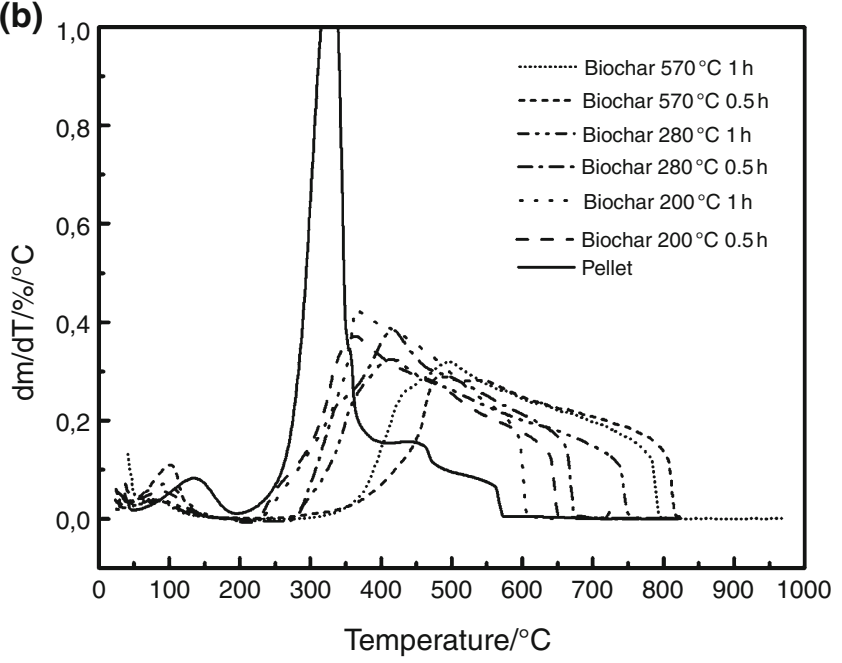

Fig. 2 TG (a) and DTG (b) curves (biochar and pine pellet), under air atmosphere and a heating rate at $30{ }^{\circ} \mathrm{C} \mathrm{min}-1$

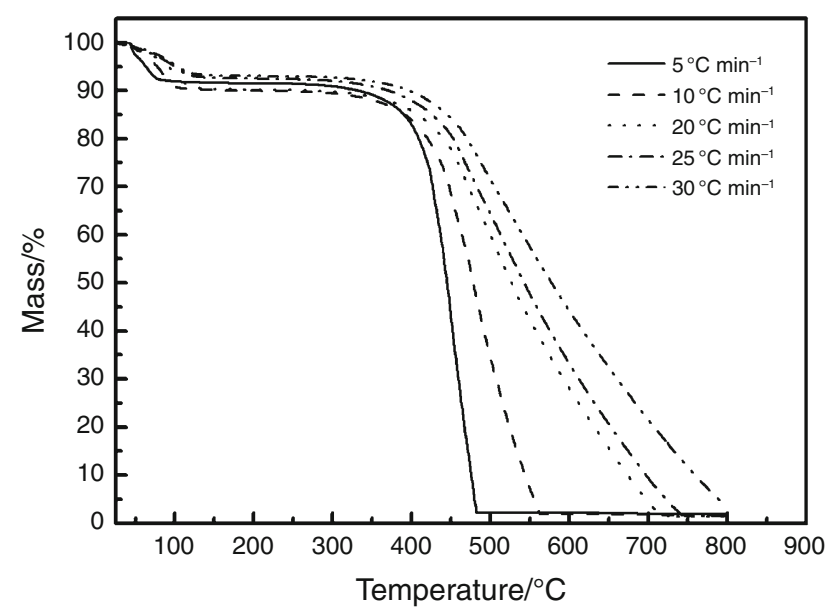

Fig. 3 TG curves under air atmosphere and heating rate at $30{ }^{\circ} \mathrm{C} \mathrm{min}-1$ for samples of biochar produced at $570^{\circ} \mathrm{C}$ of temperature residence, different heating rates and $1 \mathrm{~h}$ of residence time

method for determining surface area is described by Brunauer-Enmett-Teller model (BET); it is determined by measuring the adsorption isotherm of nitrogen gas molecules. However, the coal surface area as measured by nitrogen gas adsorption is used as a primary indicator of the activity level based on the principle that a larger surface area will have a large number of sites available for adsorption. The molecules of the employee (nitrogen) gas are very small, so that measure of surface area may be erroneous to consider the adsorption capacity of a carbon for larger molecules. These types of compounds may have limited adsorption considering the pore size [37].

The main parameters obtained were the surface area and pore diameter. The average pore size increased with increasing residence temperature. The biochar produced at
$200{ }^{\circ} \mathrm{C}$ is a micropore material $(16.9 \AA)$, whereas the biochar produced at $570{ }^{\circ} \mathrm{C}$ is a macropore material (751.0 $\mathrm{A}$ ). The average pore size increased with increasing residence temperature. The same behavior was observed for the surface area, which increased with increasing residence temperature. The biochar produced at $200{ }^{\circ} \mathrm{C}$ exhibits a very small area, $0.5349 \mathrm{~m}^{2} \mathrm{~g}^{-1}$, whereas the biochar produced at $570{ }^{\circ} \mathrm{C}$ exhibits an area of $46.4163 \mathrm{~m}^{2} \mathrm{~g}^{-1}$. It is important to note that the biochar did not undergo the activation process, so this surface area is within the parameters of the literature.

Figure 4 shows the adsorption and desorption isotherms of nitrogen to biochars produced at different residence temperatures and half an hour residence time. The biochars produced with $1 \mathrm{~h}$ of residence time showed the same behavior of adsorption-desorption isotherm of biochars produced at half an hour residence time.

The shape of the adsorption-desorption isotherm of nitrogen provides preliminary qualitative information on the adsorption mechanism and the porous structure of the adsorbent material. It was observed that in biochars produced at $200{ }^{\circ} \mathrm{C}$ and $280{ }^{\circ} \mathrm{C}$, there was a large volume adsorbed at relative pressures above 0.9 , indicating adsorption to the outer surface of the adsorbent.

In isothermal adsorption-desorption biochar produced at $570{ }^{\circ} \mathrm{C}$, a large change in the pore formation was observed at the relative pressure below 0.2 ; in other words, there was an intense formation of micropores. Note that there is not any other adsorption, indicating the absence of mesopores, and above the relative pressure of 0.9 , there is a gap between the adsorption and desorption. This hysteresis is of H4 type, often associated with narrow pores, as cracks, indicative of microporosity. 


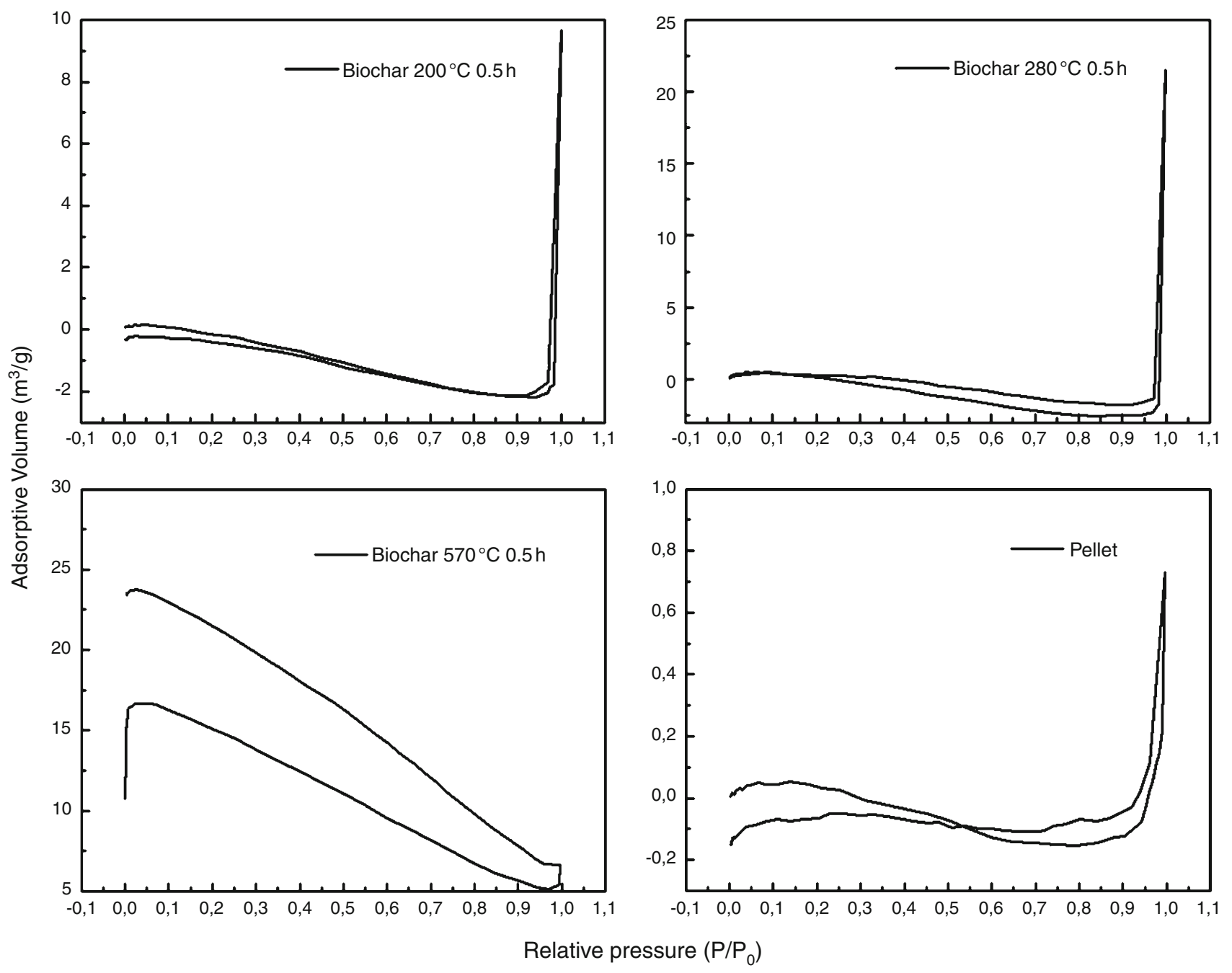

Fig. 4 Adsorption/desorption isotherm of nitrogen to pellet and biochars produced at half an hour residence time

\section{Scanning electron microscopy (SEM)}

The technique of SEM has been used to observe the physical morphology of the surface of activated carbon, allowing visualization of the characteristics of the material.

Figures 5 and 6 show SEM images of biochars and pellet. In biochars produced at 200 and $280{ }^{\circ} \mathrm{C}$, appearance of a rough surface and the rupture of the pellets into scales were observed. Upon heating at $570{ }^{\circ} \mathrm{C}$, the mass loss due to cellulose and hemicellulose thermal decomposition had already been almost completed, and as a result of these reactions, biochar structure showed high shear and much larger pores, as compared to the other biochars. These pores are formed by removing volatile in the structure of the biomass subjected to higher retention times and above $400{ }^{\circ} \mathrm{C}$ [38]. Increasing the heating rate resulted in more intense disruption of the structure of biochar.

The analysis by EDS detects the existence of the elements present in a given portion (elemental qualification).
The determination was carried out in different regions of the sample. The most important elements found were carbon and oxygen evidently in addition to calcium and potassium.

\section{Particle density}

The particle density is one of the parameters used to explain the resistance of a given carbonized material, in addition to the degradation of wood components and morphological structure thereof. It is a property that depends on the nature of the raw material (precursor material) and also on the manufacturing process of biochar.

The particle density values are shown in Table 3 . The biochars prepared in this work show great variation in particle density for temperature residence. It was hoped to increase the particle density with an increase in temperature of residence due to loss of volatile compounds from wood and mainly as a concomitant increase in 

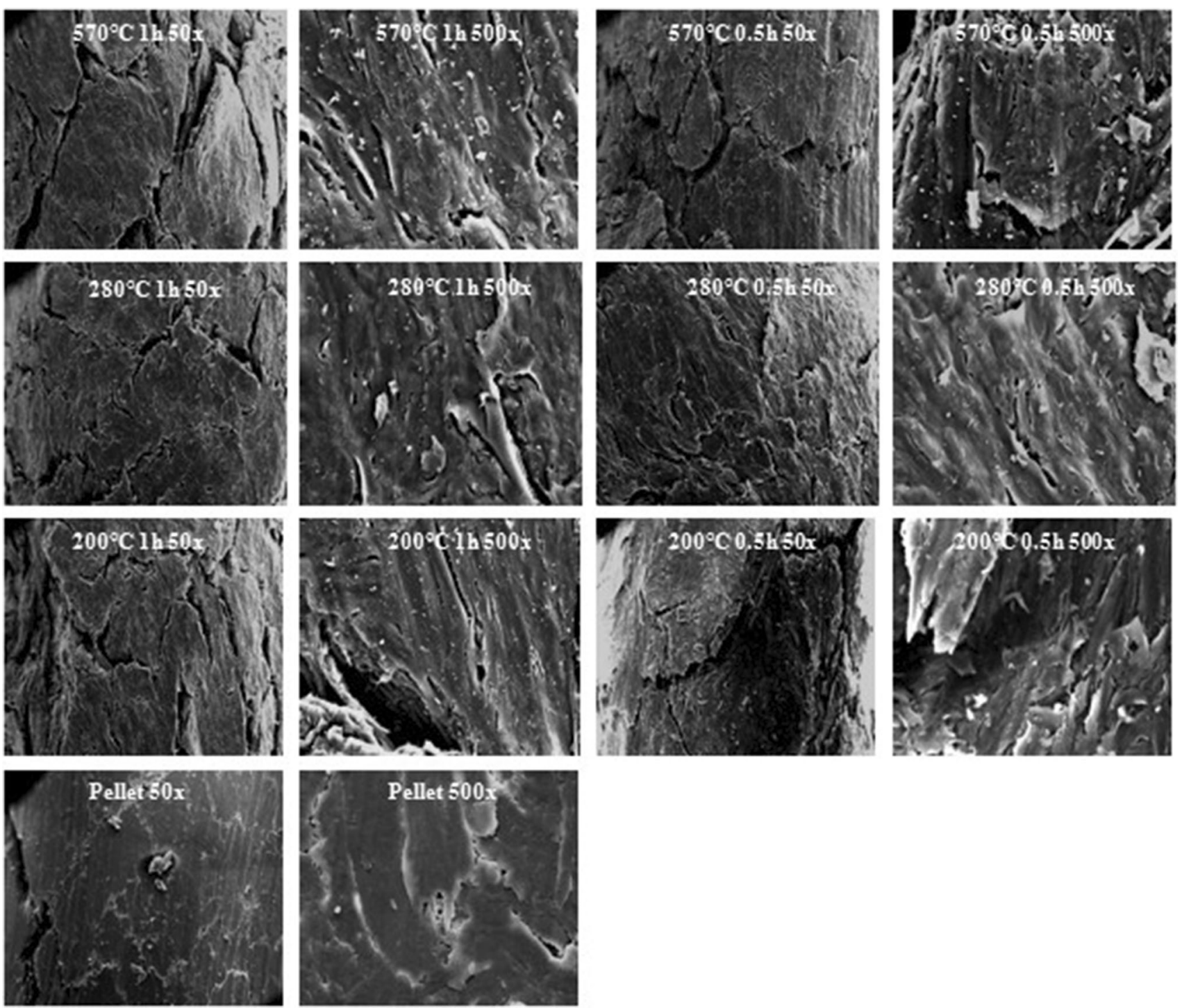

Fig. 5 Images of scanning electron microscopy of pellet and biochars produced at different residence temperatures $\left(200,280\right.$ and $\left.570{ }^{\circ} \mathrm{C}\right)$, different residence times $\left(1 \mathrm{~h}\right.$ and half an hour) at $10{ }^{\circ} \mathrm{C} \min ^{-1}$ of heating rate

structural organization of biochar in relation to the pellet. However, it was observed that the particle density decreased to $280{ }^{\circ} \mathrm{C}$ residence temperature. The reason for this phenomenon may be linked to the large formation of small pores in the structure of biochar at this temperature. As for biochar at $570{ }^{\circ} \mathrm{C}$, there is formation of large pores and cracks, with great loss of the initial compounds in pyrolyzed sample, which provides a higher particle density.

It was not possible to clearly distinguish a pattern of behavior with the increase in residence time.

\section{Porosity}

The porosity of the samples is given in Table 4 .
There has been a lower porosity in the biochar produced at $570{ }^{\circ} \mathrm{C}$ and an increase in the biochar produced at $280{ }^{\circ} \mathrm{C}$. By linking these data with SEM, it is suggested that biochar produced at $280{ }^{\circ} \mathrm{C}$ has many small pores in its internal frame, while biochar produced at $570{ }^{\circ} \mathrm{C}$ has some large pores and several cracks in its external frame.

\section{X-ray diffraction patterns}

The structures had the characteristic peaks of cellulose $\left(18.0,25.7\right.$, and $\left.40.1^{\circ}\right)$, and the diffraction of the first two peaks in pellets is more evident (Fig. 7). Pellets heated up to $280{ }^{\circ} \mathrm{C}$ present dehydration and some degradation of hemicellulose, so the cellulose diffraction apparently becomes stronger. 

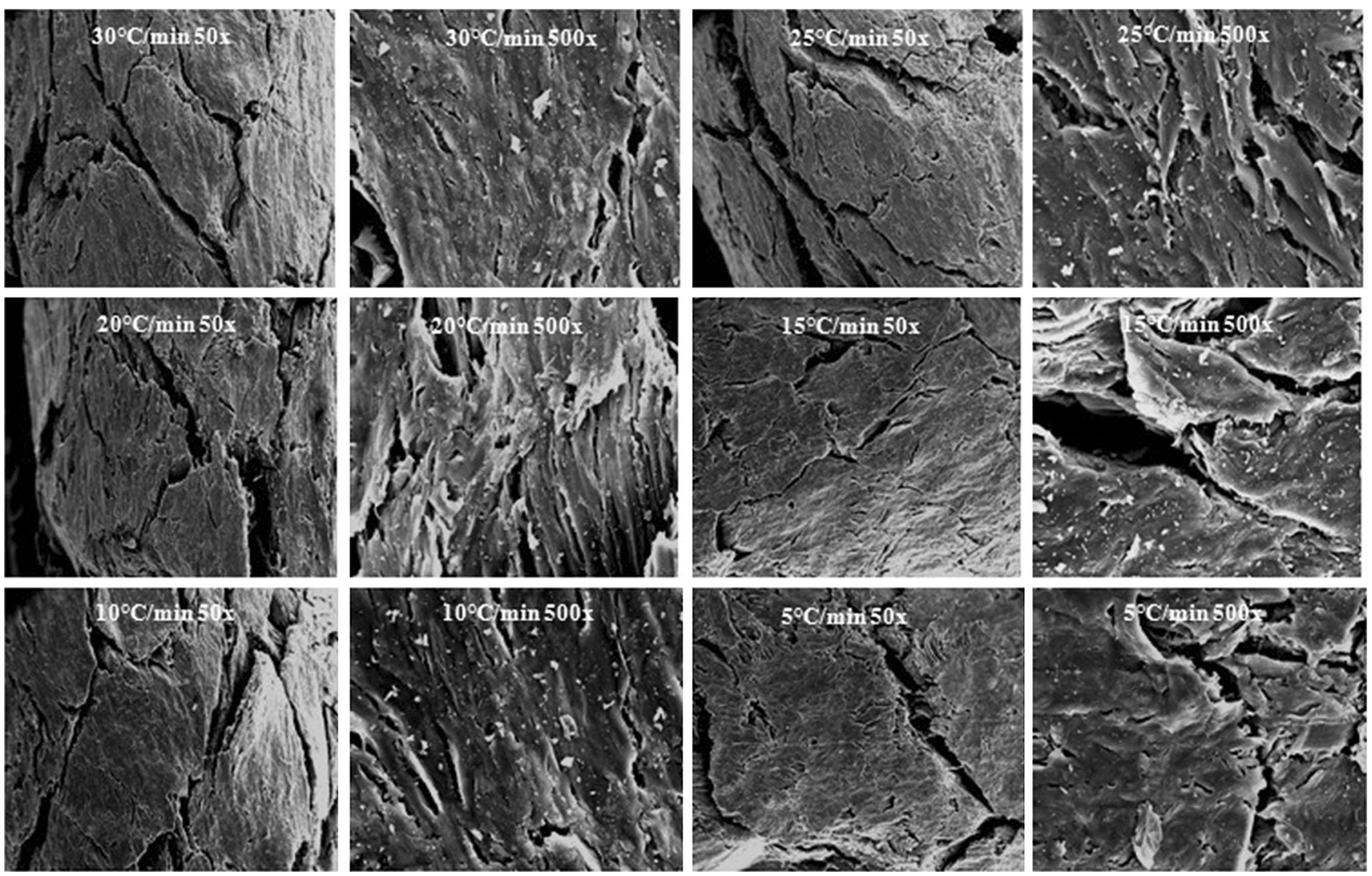

Fig. 6 Images of scanning electron microscopy of biochar produced at $570{ }^{\circ} \mathrm{C}, 1 \mathrm{~h}$ of residence time and different heating rates

Table 3 Particle density of biochars and pellet

\begin{tabular}{lll}
\hline tr/min & $T /{ }^{\circ} \mathrm{C}$ & Particle density $/ \mathrm{g} \mathrm{cm}^{-3}$ \\
\hline & Pellet & 1.3640 \\
30 & 200 & 0.5830 \\
60 & 200 & 0.5774 \\
30 & 280 & 0.4971 \\
60 & 280 & 0.4839 \\
30 & 570 & 0.8900 \\
60 & 570 & 0.8951 \\
\hline
\end{tabular}

Table 4 Porosity of the pellet and biochar

\begin{tabular}{ll}
\hline Sample & Porosity/\% \\
\hline Pellet & 11.2 \\
Biochar 570 & 41.7 \\
Biochar 280 & 68.5 \\
Biochar 200 & 62.4 \\
\hline
\end{tabular}

Upon heating to $570{ }^{\circ} \mathrm{C}$, peak cellulose disappeared, and the structure had low crystallinity. However, it is noticed that new diffraction peaks were formed around 9 and $26.4^{\circ}$. The peak at $26.4^{\circ}$ is attributed to the turbostratic arrangement that aromatic compounds shall assume [38]. Also, a subtle peak is observed in the region $51^{\circ}$, which, according Keiluweit et al. [39], is also a characteristic peak of turbostratic arrangement.

\section{Infrared spectroscopy (FTIR)}

The identification of functional groups on the surface of coal is important to determine the mechanisms responsible for the binding of contaminants in the structure of these materials. Methods for the detection of functional groups found on the surface of coal include titrimetric techniques and infrared spectroscopy [40, 41]. The infrared spectra of the pellet and biochars are shown in Fig. 7.

The FTIR spectra for pellet, as shown in Fig. 8, present several bands in the regions of 1000-1750 and $3000-3600 \mathrm{~cm}^{-1}$. O-H bonds, which may come from phenol group, carboxyl group, alcohol group, and even water. $\mathrm{O}-\mathrm{H}$ groups participating in hydrogen bonding are adsorbed in the region of $3200-3550 \mathrm{~cm}^{-1}$ [42]. The region of $1000-1750 \mathrm{~cm}^{-1}$ presents a wide range of functional groups; an exact assignment of the peaks in this region of the spectrum is difficult.

In biochars produced up to $280{ }^{\circ} \mathrm{C}$, there is a reduction in absorption in the region around $3200 \mathrm{~cm}^{-1}$, which is due 
Fig. 7 X-ray diffraction of the pellet and biochars

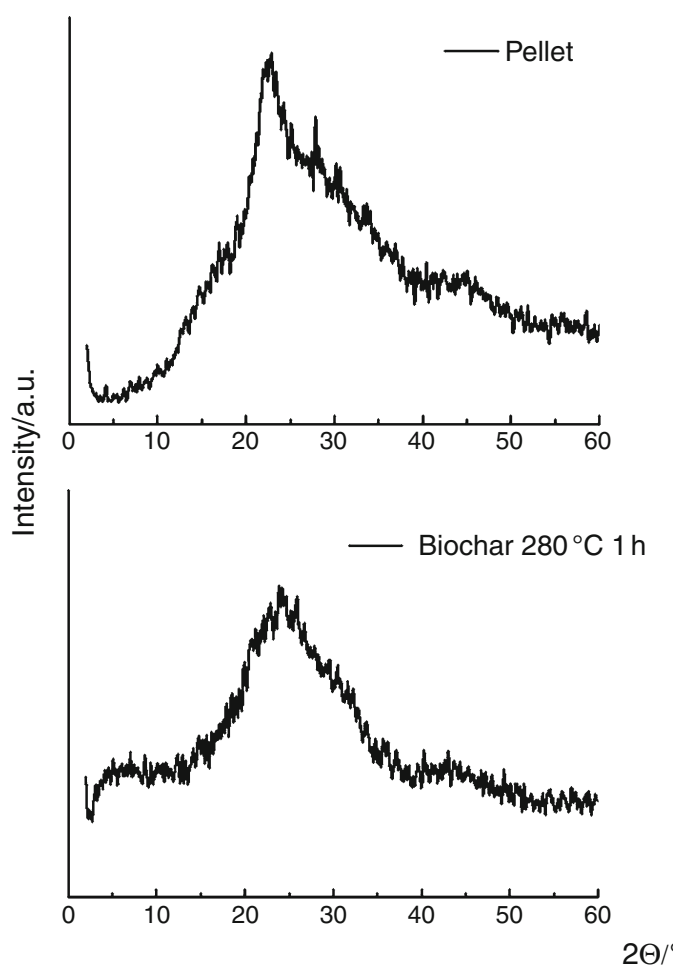

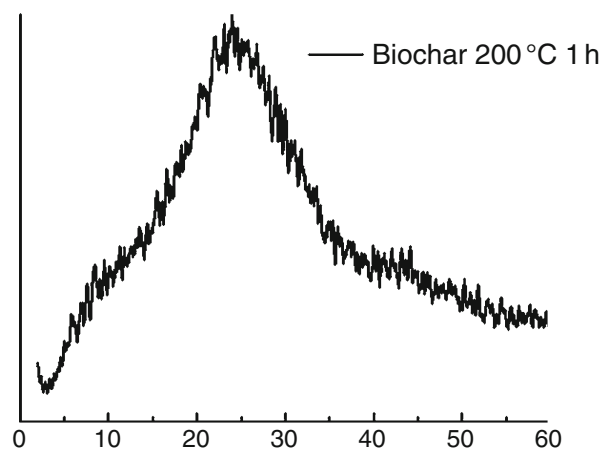
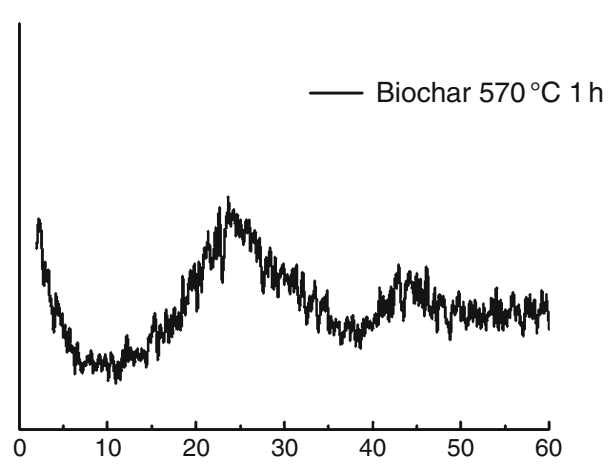

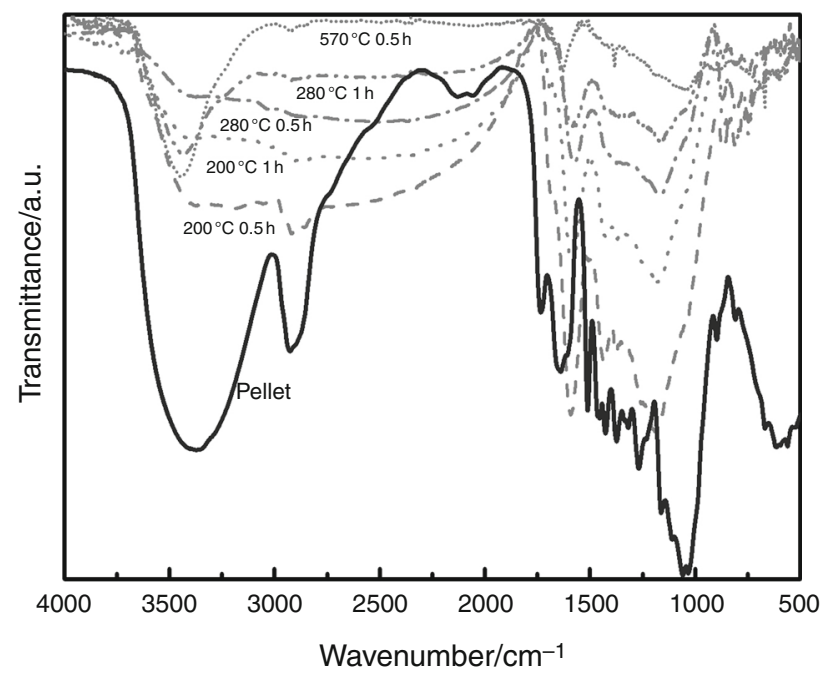

Fig. 8 Infrared spectra of the pellet and biochars

to both the loss of adsorbed water in the pellet structure and the thermal decomposition of carboxylic groups and groups $\mathrm{C}-\mathrm{H}$ attached to the aromatic structures [43]. These bands, in addition to the band around $2915 \mathrm{~cm}^{-1}$, assigned to groups of aliphatic chains $\mathrm{C}-\mathrm{H}$, practically disappear in the biochar produced at $570{ }^{\circ} \mathrm{C}$; however, there is a new band around $3420 \mathrm{~cm}^{-1}$, assigned to water that the biochar is able to adsorb with increasing pore.
There was also a reduction in absorption in the region $1000-1750 \mathrm{~cm}^{-1}$ for biochars, but all treatment groups survived until $280{ }^{\circ} \mathrm{C}$, to a greater or lesser degree. Upon heating to $570{ }^{\circ} \mathrm{C}$, most of these bands disappeared, bands before found at $1620-1735 \mathrm{~cm}^{-1}$ began to be observed between 1600 and $1700 \mathrm{~cm}^{-1}$ as a result of structural changes, or steric. As might be expected, the group $\mathrm{C}=\mathrm{C}$ of aromatic compounds $\left(1475-1600 \mathrm{~cm}^{-1}\right)$ still resisted heating at $570{ }^{\circ} \mathrm{C}$, along with the band around $1240 \mathrm{~cm}^{-1}$ $(\mathrm{C}-\mathrm{O})$.

Thus, the biochar showed characteristics of a structure consisting of polynuclear aromatic hydrocarbons with characteristic absorptions in regions of low frequencies compatible to that proposed by Van Krevelen model [44].

\section{Determination of the zero point of charge (ZPC)}

The biochar can display acidic or basic character associated with oxidation on its surface. This character is dependent on the conditions of manufacture of biochar and the temperature at which oxidation takes place. An acid biochar adsorbs appreciable amounts of bases, having little affinity for acids, while basic biochar exhibits the opposite behavior.

In this study, the value of ZPC found for all adsorbent was 8.47 , the value at which biochar acts as a buffer (Fig. 9). 


\section{Nuclear magnetic resonance (NMR)}

The ${ }^{13} \mathrm{C}$ NMR VACP-MAS solid technique was used to study the effects of the final pyrolysis temperature and residence time on the chemical structure of materials, comparing the biochar samples (Fig. 10).

The ${ }^{13} \mathrm{C}$ NMR spectra showed that biochars produced at 200 and $280{ }^{\circ} \mathrm{C}$ are very similar, maintaining the dominance of aromatic structures. However, it is possible to observe a narrowed region that refers to aromatic structures, indicating a decrease in range of different aromatic

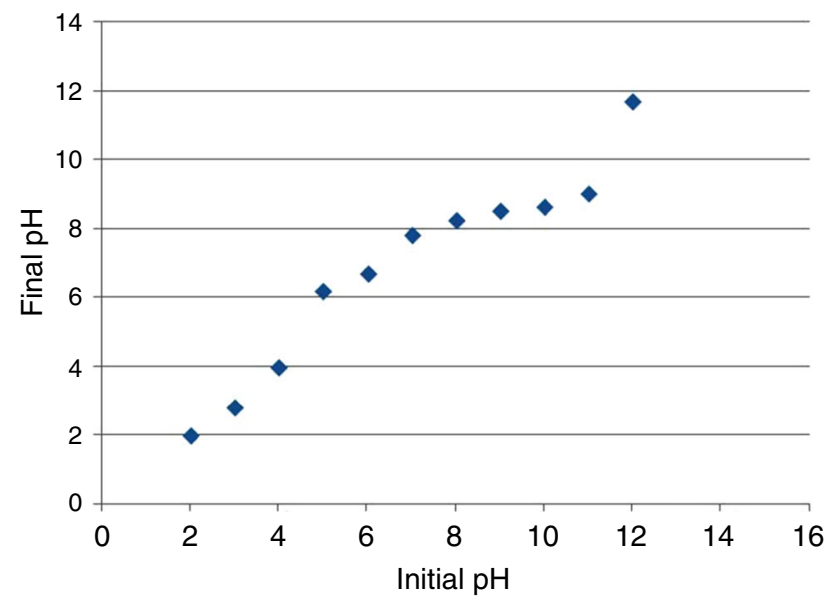

Fig. 9 Determination of the zero point of charge of the biochar structures in biochars produced at 200 and $280{ }^{\circ} \mathrm{C}$. An intense peak is observed around $130 \mathrm{ppm}$, corresponding to carbon atoms in aromatic structures with $\mathrm{sp}_{2}$ coordination, which is consistent with the turbostratic structure observed by X-ray diffraction. Other small peaks, related to carbonyl (210-145 ppm) and alkyl groups (0-90 ppm) relative to the lignin, since this is the strongest component of the pellet, which degradation is slower [45].

\section{Moisture and ash}

The moisture content, expressed as the percentage relative to the original mass, affects adsorptive capacity of biochar. For the adsorption of organic molecules, the efficiency decreases as the moisture content increases, because certain pores that would be available for adsorption are filled with water molecules.

Another important feature is the presence of minerals in the coal, which influence the measurement of the electrical conductivity of the same. Adsorbents with high mineral content have a high electrical conductivity. High electrical conductivity can restrict the application of coal, generating specific problems with unwanted catalysis of certain reactions and loss of adsorption efficiency, since the minerals can compete with the substance to be adsorbed [46].

The humidity of biochar is due to the hygroscopicity of biochars, i.e., the absorption of water from the atmosphere. By comparing the residence times, an increase in moisture
Fig. $10{ }^{13} \mathrm{C}$ NMR VACP-MAS solid spectra for biochars produced at 200 and $280{ }^{\circ} \mathrm{C}$
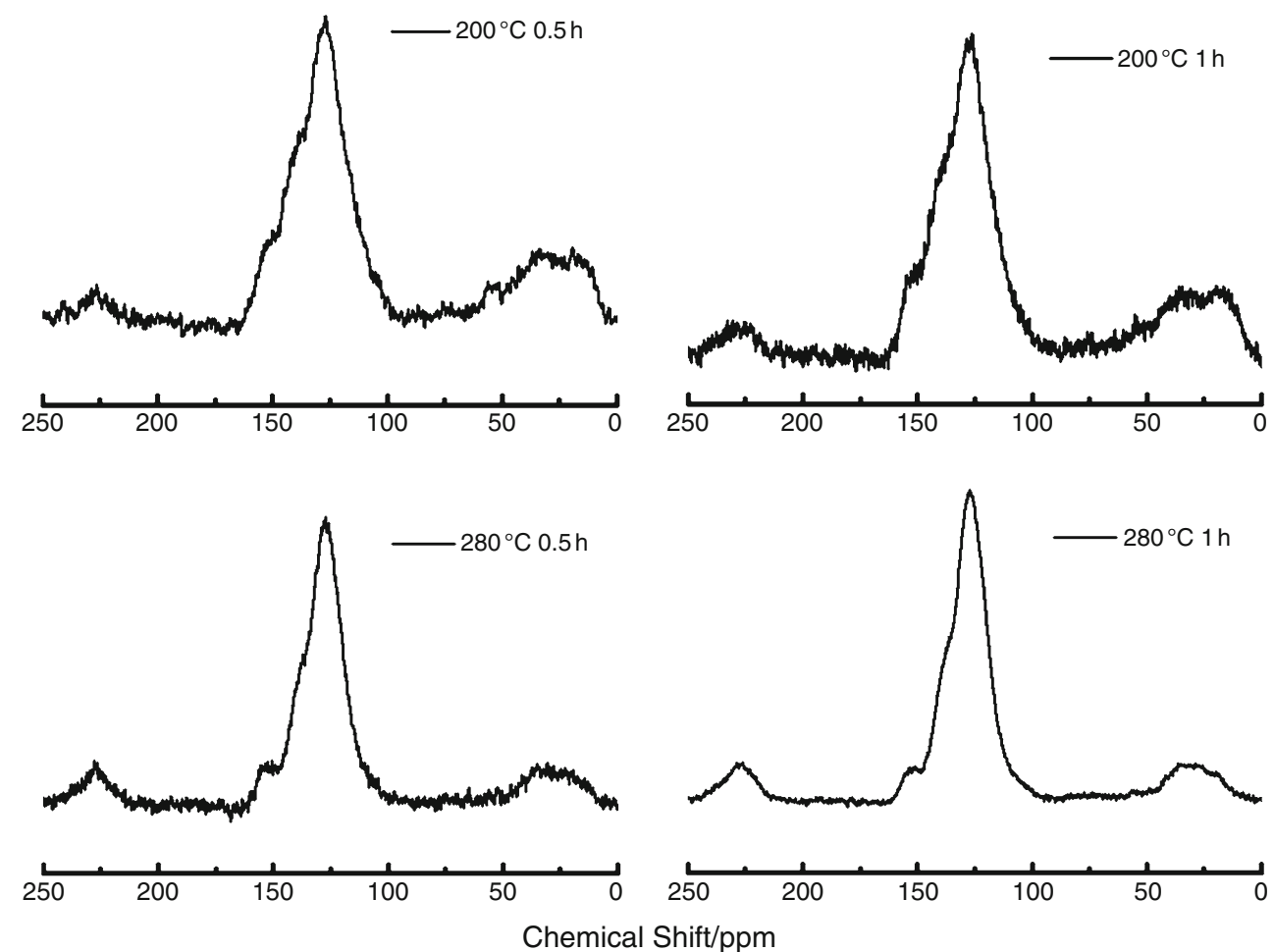
Table 5 Moisture and ash of biochars

\begin{tabular}{lll}
\hline Sample & Moisture/\% & Ash/\% \\
\hline Biochar $5701 \mathrm{~h}$ & 1.80 & 1.80 \\
Biochar $5700.5 \mathrm{~h}$ & 1.24 & 1.71 \\
Biochar $2801 \mathrm{~h}$ & 1.76 & 1.54 \\
Biochar $2800.5 \mathrm{~h}$ & 0.94 & 1.55 \\
Biochar $2001 \mathrm{~h}$ & 1.62 & 1.27 \\
Biochar $2000.5 \mathrm{~h}$ & 0.93 & 1.25 \\
\hline
\end{tabular}

of biochars was observed with increasing residence time (Table 5).

This result may be associated with an increased pore size of the biochar, mainly in that produced at $570{ }^{\circ} \mathrm{C}$, and as a result of additional loss of mass suffered in relation to other biochars. The highest moisture in pellet is associated with the hydrophilic character of cellulose and hemicellulose, which had already suffered some degradation in thermal biochars produced at $200{ }^{\circ} \mathrm{C}$. However, it is important to emphasize that the equilibrium moisture content is too low, about 0.9 to $1.8 \%$. It should be noted that commercial activated carbons are present in its technical specification, indicating a maximum moisture content of $10 \%$ [47]. Values below $10 \%$ moisture content were also obtained by other researchers in their studies, such as Garg et al. [48] with sawdust activated carbon (3.08\%).

Furthermore, tests were conducted to demonstrate the moisture resistance of biochars and it can be observed that they remained unchanged when immersed in water for several hours, which shows its hydrophobic character.

Low ash content was observed (Table 5), showing compliance to various commercial coals, usually $<10 \%$ [47, 48]. Moisture observed is the water that biochar adsorbed from the air. The biochar produced at $570{ }^{\circ} \mathrm{C}$ for $1 \mathrm{~h}$ has higher pores, justifying a higher adsorption and consequently more moisture contents.

It is observed that both results were consistent with the thermal gravimetric method, which showed low moisture content and ash.

\section{Conclusions}

The slow pyrolysis of pine pellet is effective as an alternative thermal process for the utilization of biomass residues. The process adopted led to a rapid degradation of the raw material (pine pellet) associated with an intense generation of volatile compounds, conditions that led to a reduction in density and establishment of porous structure. Biochars have basic character ( $\mathrm{pH}$ 8.47), predominance of aromatic structures, low moisture content (0.9-1.8\%), low ash content (1.25-1.80\%) and high thermal stability. Low humidity favors the adsorption and an improvement in the conservation during transport and storage.

Acknowledgements The authors acknowledge CAPES for financial support and BrBiomassa Company for pellet samples.

\section{References}

1. Scheer AP, Von Meien OF, de Toledo V, Maciel Filho R, WolfMaciel MR. A versatile equilibrium approach applied to adsorption process. AIDIC Conf Ser. 2002;5:285-92.

2. Nguyen TH, Cho HH, Poster DL, Ball WP. Evidence for a porefilling mechanism in the adsorption of aromatic hydrocarbons to a natural wood char. Environ Sci Technol. 2007;41:1212-7.

3. Chun Y, Sheng GY, Chiou CT, Xing BS. Compositions and sorptive properties of crop residue-derived chars. Environ Sci Technol. 2004;38:4649-55.

4. Bornemann LC, Kookana RS, Welp G. Differential sorption behavior of aromatic hydrocarbons on charcoals prepared at different temperatures from grass and wood. Chemosphere. 2007;67:1033-42.

5. Chen B, Chen Z. Sorption of naphthalene and 1-naphthol by biochars of orange peels with different pyrolytic temperatures. Chemosphere. 2009;76:127-33.

6. Chen B, Yuan M. Enhanced sorption of polycyclic aromatic hydrocarbons by soil amended with biochar. J Soils Sediments. 2011;11:62-71.

7. Shafizadeh F, Sekiguchi Y. Development of aromaticity in cellulosic chars. Carbon. 1983;21:511-6.

8. Malik PK. Use of activated carbons prepared from sawdust and rice-husk for adsorption of acid dyes: a case study of acid yellow 36. Dyes Pigments. 2003;56:239-49.

9. Soldatkina LM, Sagaidak EV, Menchuk VV. Adsorption of cationic dyes from aqueous solutions on sunflower husk. J Water Chem Techno. 2009;31:238-43.

10. Qiu Y, Zheng Z, Zhou Z, Sheng GD. Effectiveness and mechanisms of dye adsorption on a straw-based biochar. Bioresour Technol. 2009;100:5348-51.

11. Beesley L, Marmiroli M. The immobilization and retention of soluble arsenic, cadmium and zinc by biochar. Environ Pollut. 2011;159:474-80.

12. Uchimiya M, Lima IM, Klasson KT, Chang SC, Wartelle LH, Rodgers JE. Immobilization of heavy metal ions (Cu-II, Cd-II, $\mathrm{Ni}-\mathrm{II}$ and $\mathrm{Pb}$-II) by broiler ltter-derived biochars in water and soil. J Agr Food Chem. 2010;58:5538-44.

13. Mohana D, Pittman CU Jr, Brickab M, Smithc F, Yanceyd B, Mohammadb J, Steelee PH, Alexandre-Francof MF, GómezSerranof V, Gongg H. Sorption of arsenic, cadmium, and lead by chars produced from fast pyrolysis of wood and bark during biooil production. J Colloid Interf Sci. 2007;310:57-73.

14. Cao XD, Ma LN, Gao B, Harris W. Dairy-manure derived biochar effectively sorbs lead and atrazine. Environ Sci Technol. 2009;43:3285-91.

15. Liu Z, Zhang F. Removal of lead from water using biochars prepared from hydrothermal liquefaction of biomass. J Hazard Mater. 2009;167:933-9.

16. Wilson JA, Pulford ID, Thomas S. Sorption of $\mathrm{Cu}$ and $\mathrm{Zn}$ by bone charcoal. Environ Geochem Health. 2003;25:51-6.

17. Mortula M, Gibbons M, Gagnon G. Phosphorus adsorption by naturally-occurring material and industrial by-products. J Environ Eng Sci. 2007;6:157-64. 
18. Bridgwater AV. Renewable fuel and chemicals by thermal processing of biomass. Chem Eng J. 2003;91:87-102.

19. Barret EP, Joyner LG, Halenda PP. Characterization of Solids in General and Catalysts in Particular. J Am Chem Soc. 1951;73: 373-80.

20. Brunelle JP. Preparation of catalysts by metallic complex adsorption on mineral oxides. Pure Appl Chem. 1978;50(9-10): 1211-29.

21. Guilarduci VVS, Mesquita JP, Martelli PB, Gorgulho HF. Phenol adsorption on commercial active carbon under alkaline conditions. Quim Nova. 2006;29(6):1226-32.

22. ASTM D792-13. standard test methods for density and specific gravity (relative density) of plastics by displacement, ASTM International, West Conshohocken, PA, 2013.

23. Oliveira AC, De Carneiro ACO, Vital BR, Almeida W, Pereira BLC, Cardoso MT. Quality parameters of Eucalyptus pellita F. Muell. wood and charcoal. For Sci. 2010;87:431-9.

24. ASTM D3173-11, Standard test method for moisture in the analysis sample of coal and coke, ASTM International, West Conshohocken, PA, 2011.

25. ASTM D3174-12, standard test method for ash in the analysis sample of coal and coke from coal, ASTM International, West Conshohocken, PA, 2012.

26. ASTM D1762-84(2013), Standard test method for chemical analysis of wood charcoal, ASTM International, West Conshohocken, PA, 2013.

27. Marcilla A, Garcia-Garcia S, Asensio A, Conesa JA. Influence of thermal treatment regime on the density and reactivity of activated carbons from almond shells. Carbon. 2000;38:429-40.

28. Bridgwater AV. Principles and practice of biomass fast pyrolysis process for liquids. J Anal Appl Pyrol. 1999;51(1-2):3-22.

29. Bridgwater AV. Review of fast pyrolysis of biomass and product upgrading. Biomass Bioenergy. 2012;38:68-94.

30. Dermibas A. Pyrolysis of ground beech wood in irregular heating rate conditions. J Anal Appl Pyrol. 2005;73:39-43.

31. Ranzi E, Cuoci A, Faravelli T, Frassoldati A, Migliavacca G, Pierucci S, Sommariva S. Chemical kinetics of biomass pyrolysis. Energy Fuels. 2008;22:4292-300.

32. Gracia-Perez M, Wang S, Shen J, Rhodes MJ, Lee WJ, Li CZ. Effects of temperature on the formation of lignin-derived oligomers during the fast pyrolysis of Mallee woody biomass. Energy Fuels. 2008;22:2022-32.

33. Yang H, Yan R, Chen H, Lee DH, Zheng C. Characteristics of hemicelluloses, cellulose and lignin pyrolysis. Fuel. 2007;86: 1781-8.
34. Antal MJ, Gronli M. The art, science and technology of charcoal production. Eng Chem Res. 2003;42:1619-40.

35. Morais SAL, Nascimento EA, Melo DC. Chemical analysis of Pinus oocarpa wood part I-quantification of macromolecular components and volatile extractives. Revista Árvore. 2005;29(3):461-70.

36. Wooten JB, Seeman JI, Hajaligol MR. Observation and characterization of cellulose pyrolysis intermediates by 13C CPMAS NMR. A new mechanistic model. Energy Fuel. 2004;18:1-15.

37. Ismadji S, Sudaryanto Y, Hartono SB, Setiawan LEK, Ayucitra A. Activated carbon from char obtained from vacuum pyrolysis of teak sawdust: pore structure development and characterization. Bioresour Technol. 2005;96:1364-9.

38. Sharma RK, Wooten JB, Baliga VL, Lin X, Chan WG, Hajaligol MR. Characterization of chars from pyrolysis of lignin. Fuel. 2004;83:1469-82.

39. Keiluweit M, Nico PS, Johnson M, Kleber M. Dynamic molecular structure of plant biomass-derived black carbon (biochar). Environ Sci Technol. 2010;44:1247-53.

40. Lima IM, Marshall WE. Granular activated carbons from broiler manure: physical, chemical and adsorptive properties. Biosour Technol. 2005;96:699-706.

41. El-Hendawy AA. Surface and adsorptive properties of carbons prepared from biomass. Appl Surf Sci. 2005;252:287-95.

42. Silverstein RM, Webster FX, Kiemle DJ. Spectrometric identification of organic compounds. 7th ed. Hardcover: Wiley; 2005.

43. Figueiredo JL, Pereira MFR, Freitas MMA, Órfão JJM. Modification of the surface chemistry of activated carbons. Carbon. 1999;37:1379-89.

44. Lohmann TW. Modelling of reactions in coal pyrolysis. Ph.D. thesis, Institute of Applied Mathematics and statistics, Munich University of Technology, Munchen, Germany; 2001.

45. Brewer CE, Schimidt-Rohr K, Satrio JA, Brown RC. Characterization of biochar from fast pyrolysis and gasification systems. Environ Prog Sustain Energy. 2009;28(3):386-96.

46. Ng C, Losso JN, Marshall WE, Rao RM. Physical and chemical properties of selected agricultural byproduct-based activated carbons and their ability to adsorb geosmin. Biosour Technol. 2002;84:177-85.

47. Marton JM, Felipe MGA, Silva JBAE, Pessoa Júnior A. Evaluation of activated charcoals and conditions of adsorption on hemicellulosic hydrolyzate treatment of sugarcane bagasse using design of experiments. Analytica. 2003;3:45-54.

48. Garg VK, Gupta R, Yadav AB, Kumar R. Dye removal from aqueous solution by adsorption on treated sawdust. Bioresour Technol. 2003;89:121-4. 